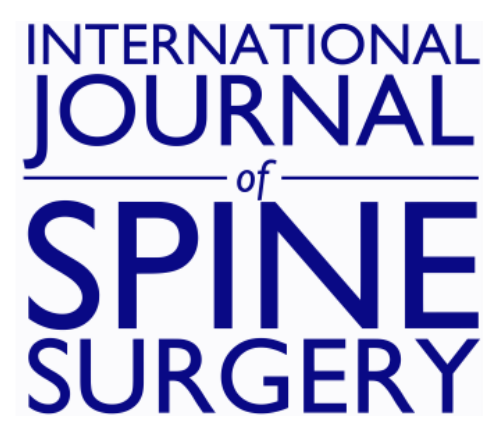

\title{
Distal Junctional Failure Secondary to Nontraumatic Fracture of Lower Instrumented Vertebra: Our Experience and Review of Literature
}

Akash Hosthota, Ramachandran Govindasamy and Satish Rudrappa

Int J Spine Surg published online 22 September 2021

http://ijssurgery.com/content/early/2021/09/20/8131

This information is current as of April 26, 2023.

Email Alerts Receive free email-alerts when new articles cite this article. Sign up at:

http://ijssurgery.com/alerts 


\title{
Distal Junctional Failure Secondary to Nontraumatic Fracture of Lower Instrumented Vertebra: Our Experience and Review of Literature
}

\author{
AKASH HOSTHOTA, RAMACHANDRAN GOVINDASAMY, SATISH RUDRAPPA \\ Department of Spine Surgery, Institute of Neurosciences, Sakra World Hospital, Bellandur, Bangalore, India
}

\begin{abstract}
Background: Junctional kyphosis ( $\mathrm{JK}$ ) is usually observed in long-level instrumented fusion surgeries. Various contributing factors are proposed, the pre-existing and postoperative spinal imbalance is considered as the single most important factor for the development of JK in adult spinal deformity surgeries. Distal JK (DJK) is seldom reported compared to proximal JK (PJK), and scarce literature exists.

Methods: We report 2 unique cases of distal junctional failure (DJF) with worsening of neurology, secondary to nontraumatic fracture of a lower instrumented vertebra operated for thoracic canal stenosis without deformity. The first case had acute worsening of the Neurology during follow up and on evaluation, the supine CT and MRI scan revealed well decompressed spinal canal, no implant migration to the canal, no screw loosening, or rod failure. Supine sitting radiographs demonstrated DJK with Fracture and the patient underwent extension of fusion till the pelvis with 3-rod construct and interbody fusion, because of the instability at the L1 level.

The second case remained neurologically stable for a month and then had an acute onset of back pain, sensory deficit, and urine incontinence. The supine-sitting dynamic radiograph done demonstrated L1 fracture with DJK at D12-L1 levels. The patient was counseled for extension of fusion, which was deferred by the patient.

Results: Patients in our series, had an acute worsening of neurological deficit within a month of posterior spinal fixation. Their supine imaging was almost normal, and the diagnosis of DJK with L1 fracture instability was possible only on a supine-sitting dynamic radiograph. Various factors like obesity, TL kyphosis, osteoporosis, etc. can be the attributing factors for the development of DJK

Conclusion: A high index of suspicion is required for diagnosing nontraumatic fracture in long-level fusion patients with acute neurological worsening. The supine-sitting dynamic radiograph is an important diagnostic tool for DJF in patients having difficulty standing erect.

Level of Evidence: 4.

Clinical Relevance: Application of sitting and supine dynamic radiographs to diagnose instability in patients unable to stand for flexion and extension radiographs.

Complications

Keywords: Proximal junctional failure, dynamic radiograph, Junctional kyphosis
\end{abstract}

\section{INTRODUCTION}

Junctional kyphosis (JK) is defined as $10^{\circ}$ or more of angulation adjacent to the proximal or distal level of the fused spinal segment. ${ }^{1}$ It is usually observed in long level instrumented fusion surgeries for adolescent idiopathic scoliosis ${ }^{2}$ or Scheuermann's kyphosis, ${ }^{3}$ but it is increasingly seen in adult spinal deformity surgeries as well. ${ }^{4}$ Proximal JK (PJK) is the most commonly reported entity in literature. ${ }^{5,6}$ These patients have symptomatology ranging from no symptoms, axial pain, implant prominence to neurological compromise. ${ }^{7}$ Various contributing factors like age, obesity, osteoporosis, levels of upper instrumented vertebra (UIV), lower instrumented vertebra (LIV), and degree of deformity correction are proposed. However, the preexisting and postoperative spinal imbalance is considered as the single most important factor for the development of $\mathrm{JK}$ in adult spinal deformity surgeries. ${ }^{8}$ The various presentations of distal JK (DJK) are progressive degeneration of disc spaces, acute wedging of disc, instrumentation failure, or adjacent level vertebral fracture. ${ }^{9}$ To date, there has been no case reported of DJK secondary to nontraumatic fracture of LIV in a nondeformity fusion surgery. 
We report 2 unique cases of distal junctional failure (DJF) with nontraumatic fracture of LIV in a long level fusion surgery for thoracic canal stenosis without deformity.

\section{CASE PRESENTATIONS}

\section{Case 1}

A morbidly obese 58-year-old presented with thoracic myelopathy and preserved bladder continence secondary to multilevel calcified ligamentum flavum. The patient was relatively normal 3 months before the time of admission, except for occasional numbness in legs. The patient sustained an accidental fall from a chair and noticed progressive weakness in the lower limb over a period of 3 months from Nurick grade 4 to 5 . At the time of admission, the tone of bilateral lower limbs was spastic with power $0 / 5$ in the left lower limb and $2 / 5$ on the right. The sensations on the right side $(2 / 3)$ were relatively spared with significant reduction on the left side $(1 / 3)$ from below D8. Reflexes in bilateral lower limbs was increased with extensor plantar, suggestive of spinal cord involvement. Upper limb and bladder neurological examinations were normal. Magnetic resonance imaging (MRI) of the spine revealed multilevel thoracic canal stenosis and ligamentum flavum calcification, with major stenosis at D9-D10, followed by D6-D7, D7-D8, and D10-11. Spinal cord hyperintensity signal change was evident at the D10 level, and it correlated with the clinical neurological levels. In addition to thoracic canal stenosis, multilevel lumbar canal stenosis was also noticed. A computed tomography (CT) scan was done as a part of preoperative planning which ruled out fractures of the spine and demonstrated calcifications in the ligamentum flavum with disc osteophyte complex in various levels (Figure 1).

In view of thoracic spinal cord involvement, obesity, and limited ambulatory status, advised thoracic decompression with instrumentation and lumbar decompression was planned at a later date if symptomatic. The patient underwent uneventful T4-L1 fusion with pedicle screw fixation density of 1.4, wide laminectomy, and decompression at D6-7, D7-8, and D10-11 levels under intraoperative neural monitoring. Postoperatively (Figure 2), there was a steady and gradual improvement in the lower limb neurology, with rehabilitation at bed side in supine and sitting position. At 2 weeks after completion of surgery, the patient had an acute worsening of the preexisting neurology with bowel and bladder incontinence.

The patient was readmitted with flaccid paraplegia of the bilateral lower limbs (motor power $=0 / 5$, sensory right lower limb $=1 / 3$ and left $=0 / 3$ from below L1) with the absence of reflexes and incontinence. In view of the acute worsening of the postspinal fixation, pedicle screw migration inside the canal with implant failure was considered as the first clinical diagnosis, with transverse myelitis, hematoma, or abscess-related canal stenosis as differentials. Magnetic resonance imaging of the spine with contrast and a CT scan was done for further evaluation (Figure 3).

The CT scan revealed no implant migration to canal, no screw loosening, or rod failure. The MRI of the spine revealed an adequately decompressed spinal cord at operated levels, with no evidence of new cord changes or canal stenosis. Considering a flaccid paraplegia and a new sensory level of L1, a pathology distal to the fusion level was suspected, and a dynamic radiograph in sitting-supine position was done for further evaluation. To our surprise, the radiograph demonstrated a gross distal junctional L1-2 kyphosis in sitting radiograph with near to normal alignment in supine radiograph. A retrospective review of the $\mathrm{CT}$ done in supine position demonstrated a hairline fracture of the posteroinferior corner of the L1 vertebral body with doubtful pars fractures (Figure 4). The patient was taken for extension of fusion down to the pelvis with 3 -rod construct and interbody fusion at L1-2, L4-5, and L5-S1 levels with decompression (Figure 5). Intraoperative fracture hematoma was found at L12 levels which was not visible in the MRI due to metal artifact. There was also rupture of the posterior ligamentous complex with significant instability of the spine at L1 fracture level (Figure 6). The postoperative status was complicated with multiple issues like wound infection, bed sores, and deep vein thrombosis, and finally, the patient succumbed at 3 months post-surgery.

\section{Case 2}

A 66-year-old patient with thoracic myelopathy (Nurick grade 5) secondary to thoracic canal stenosis was admitted with progressive weakness of bilateral lower limbs for a period of 6 months. The patient was averagely built, with $\mathrm{T}$ Score of -2.8 , suggestive of osteoporosis. At the time of 

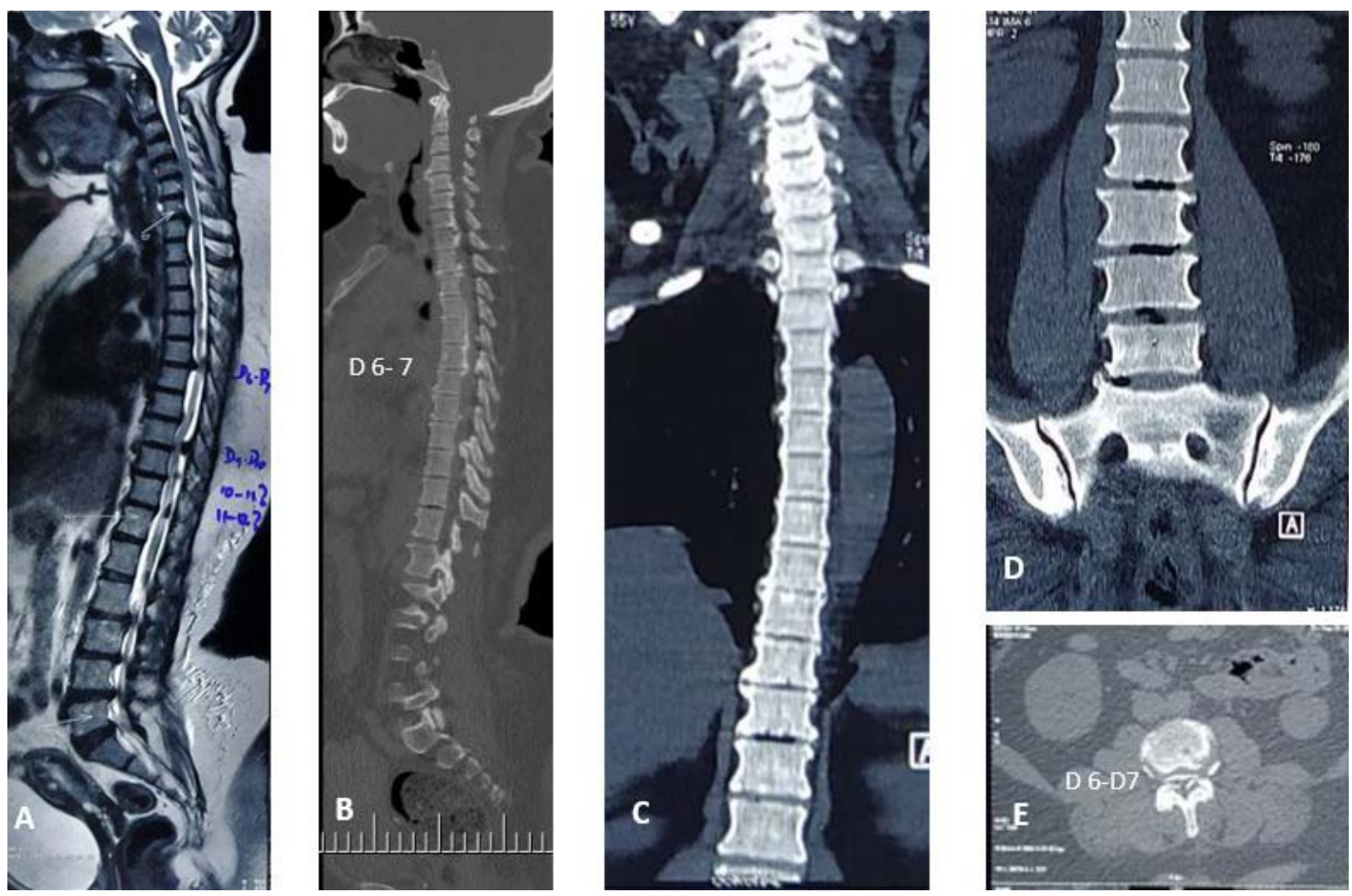

Figure 1. Figure 1: (A-E) Of Case 1 (A) Pre-operative sagittal MRI of whole spine showing multi-level canal stenosis; (B) Sagittal CT showing ossified ligamentum flavum and posterior longitudinal ligament; (C, D) Coronal CT image of whole spine (E) Axial CT at D6-D7 with maximum stenosis.
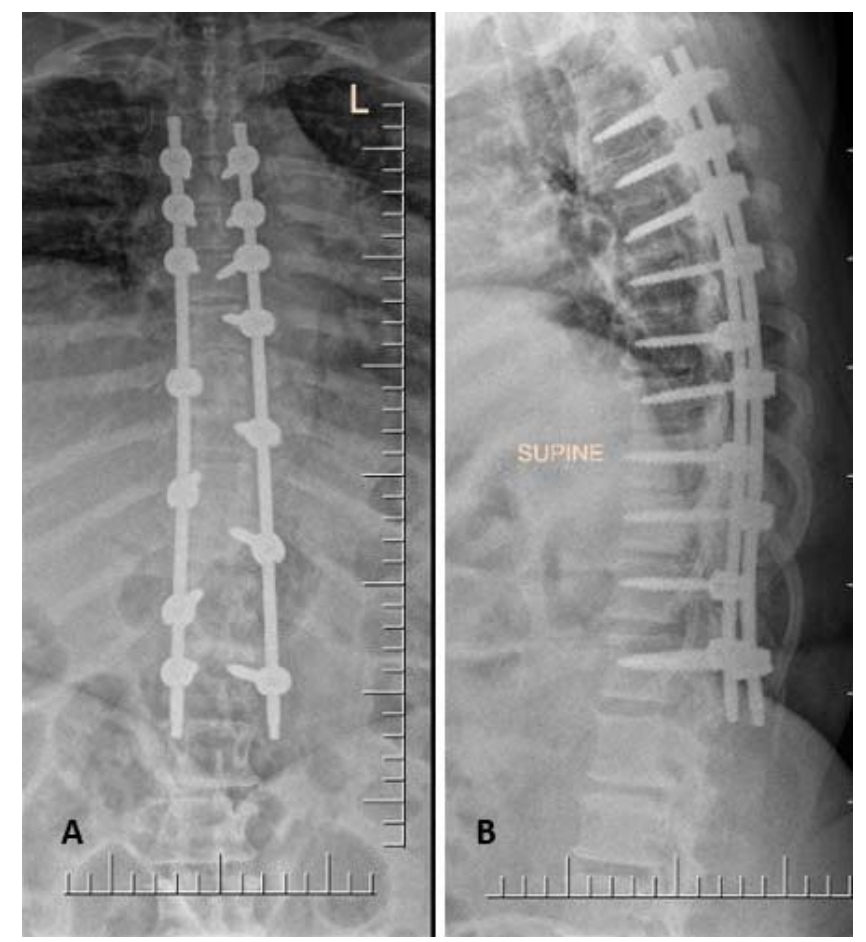

Figure 2. (A, B) Immediate post-operative $X$ ray of case 1 after decompression and posterior instrumentation. (A) Antero posterior view, (B) Supine lateral view. admission, the neurological motor examination revealed spastic legs with power of $1 / 5$ in bilateral legs and preserved sensations. On radiologic examination, maximal canal stenosis was found at the
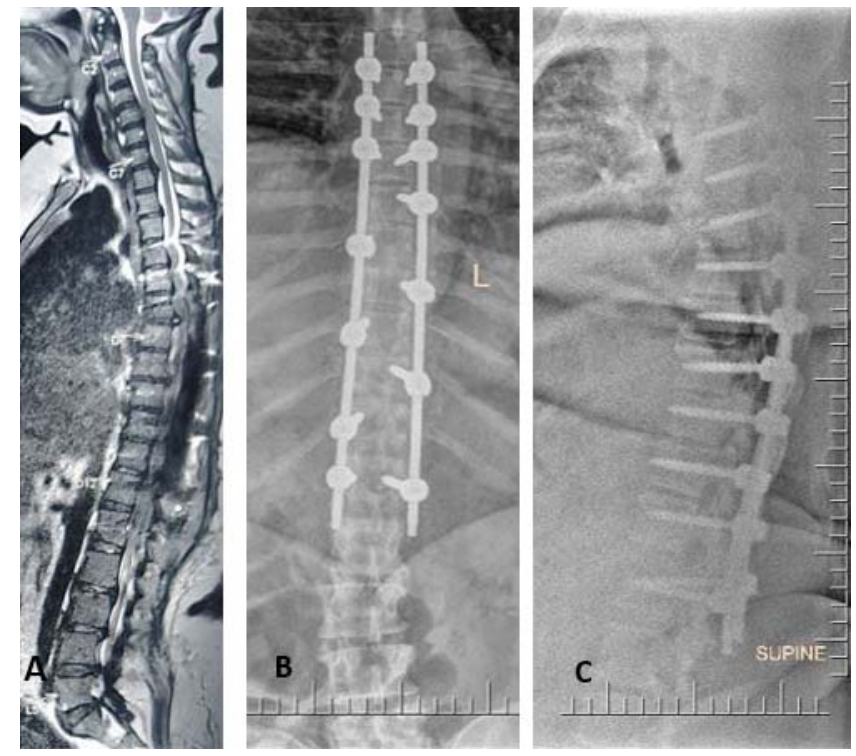

Figure 3. (A-C) $M R I$ and $X$ ray investigation after onset of neurological deterioration in case 1. (A) Sagittal MRI showing adequate decompression, (B) Supine AP X ray and (C) Supine lateral $X$ ray of thoraco- lumbar spine. 

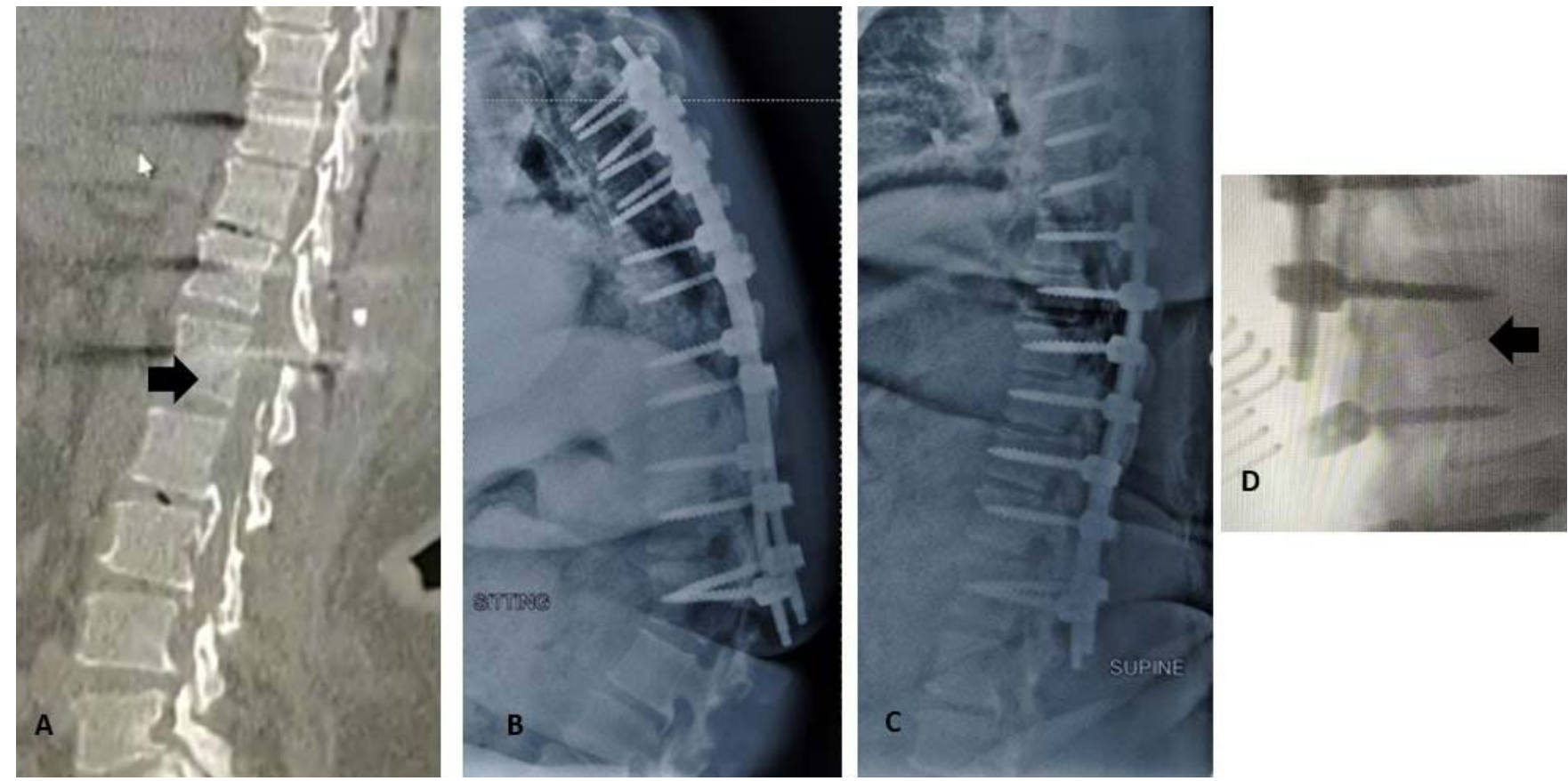

Figure 4. (A-C) Retrospective analysis of the chance fracture. (A) Hairline fracture at posterior inferior corner of L1 vertebra, (B, C) Dynamic instability and failure at the LIV in sitting and supine position, (D) Intra operative image intensifier fracture displacement at L1 corner, secondary to prone position.

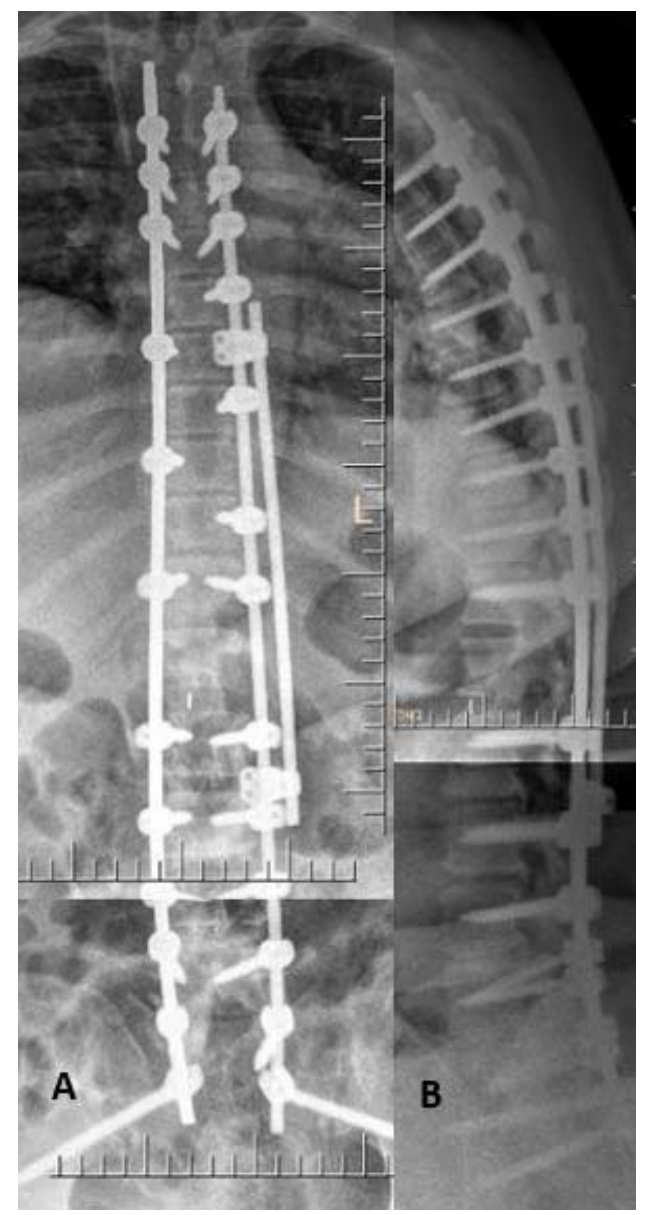

Figure 5. (A, B) Post-operative radiograph of extension of posterior instrumented fusion till pelvis, (A) AP view, (B) lateral view level of D6-7 with spinal cord signal changes (Figure 7). Apart from this level, significant canal stenosis was noted at D1-3, D7-8, and D11-12 levels secondary to ligamentum flavum hypertrophy and calcifications, and the patient was found to have a rigid thoracolumbar kyphosis, evident even on supine MRI. The patient was taken for $\mathrm{C} 7-\mathrm{L} 1$ spinal instrumented fusion with 1.07 pedicle screw density and decompression with D1, D2, D7, D11, and D12 laminectomy under intraoperative neural monitoring (Figure 8). The lumbar levels were not addressed, considering the clinical presentation of thoracic myelopathy without cauda equina features. The patient remained neurologically stable for a

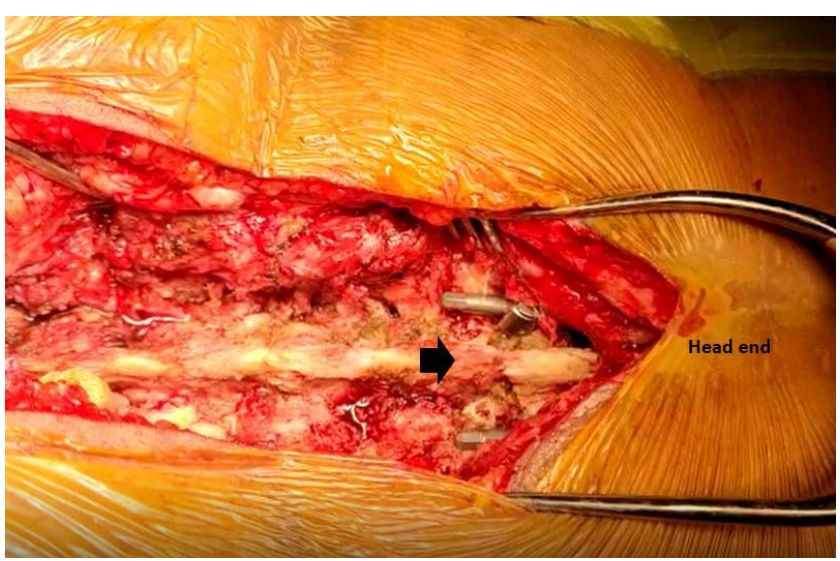

Figure 6. Intra operative image (arrow) showing the discontinuity in the posterior elements, which was mobile with manipulation. (Case 1) 

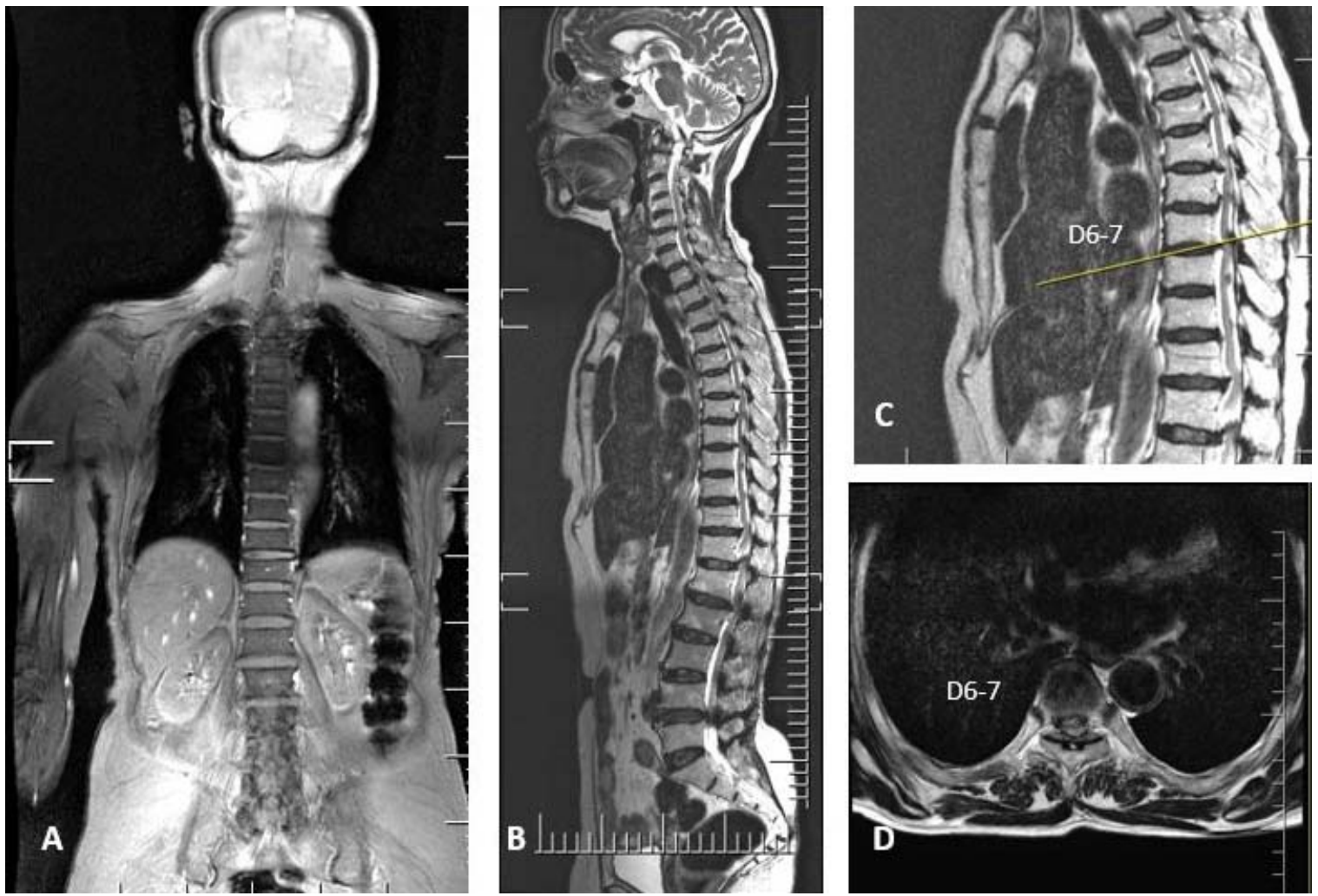

Figure 7. Pre-operative sagittal MRI of Case 2, showing canal stenosis at multi-level with cord changes maximum at D6-D7. (A) Coronal, (B, C) Sagittal view; (D) Axial view.
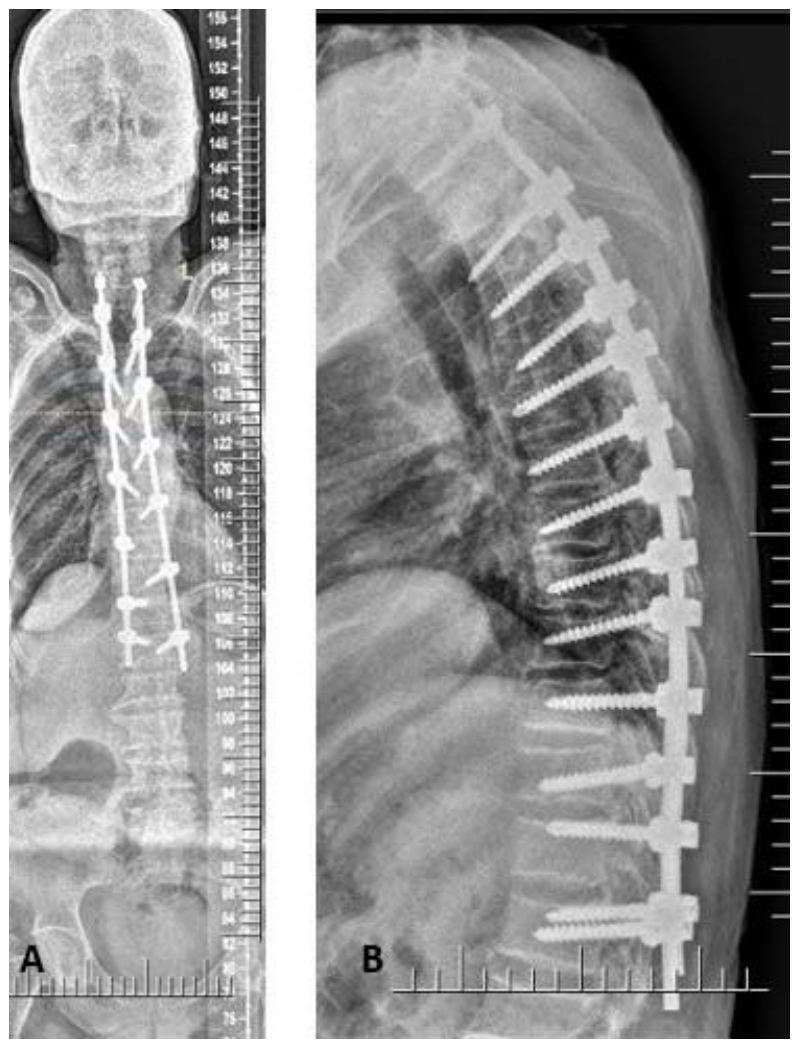

Figure 8. (A-B) Immediate supine post-operative radiograph of case 2 (A) AP view, (B) lateral view. month and then had an acute onset of back pain, sensory deficit, and urine incontinence. The supinesitting dynamic radiograph done demonstrated L1 fracture with DJK at D12-L1 levels (Figure 9). The patient was counseled for extension of fusion, which was deferred by the patient.

\section{DISCUSSION}

Distal JK is a relatively less discussed term in literature because of less prevalence than PJK. ${ }^{4}$ Usually, patients with DJK are asymptomatic with mild to moderate back pain, which is a result of accelerated degeneration of disc and/or loosening of implants. In our cases, the patients had acute worsening of the neurological deficits secondary to nontraumatic fracture at the thoracolumbar junction, which has never been reported in the literature. $\mathrm{Hu}$ et $\mathrm{al}^{11}$ reported a very similar case at the proximal level of $\mathrm{T} 2-\mathrm{L} 1$ fusion for thoracic kyphosis surgery. In their case report, the patient sustained a nontraumatic T2 fracture within 2 weeks of surgery with no neurological deficits. The proposed cause of such a fracture in his case was osteoporosis and was managed with extension of fusion along with teriparatide injection. ${ }^{11}$ Tan et al ${ }^{12}$ 

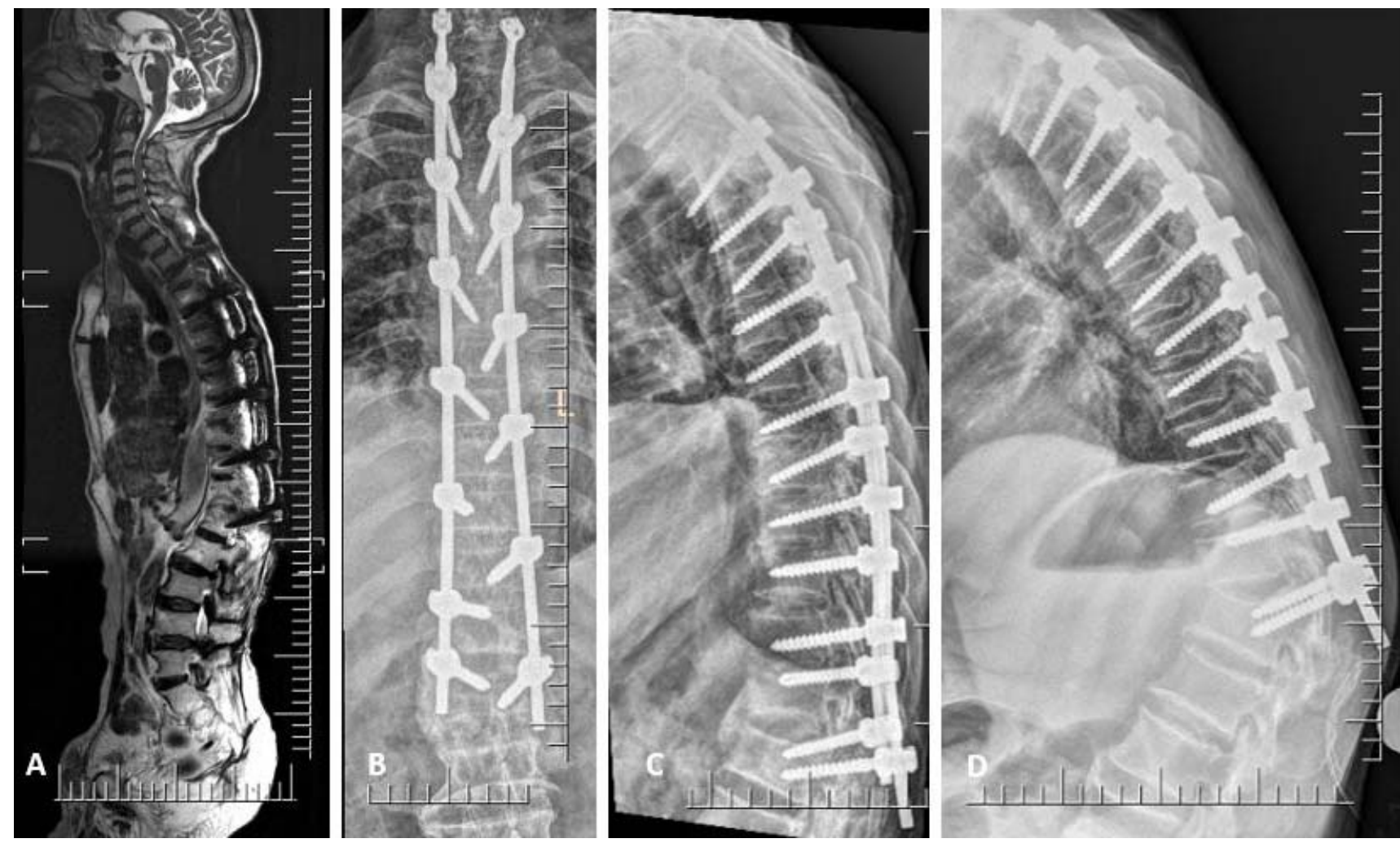

Figure 9. (A-D) MRI and X ray investigation after onset of neurological deterioration in case 2. (A) MRI showing adequate decompression, (B) AP view of thoracolumbar spine, (C) supine lateral view of spine showing change in the direction of LIV screw, so this was followed by, (D) sitting lateral view showing failure at LIV with kyphosis D12-L1.

reported 2 cases of osteoporotic L5 vertebral body compression fractures in post lumbar fusion patients at the end of 6 months and attributed it to LIV selection (Table). The L5 lumbar vertebra is more prone because of the varied lumbar spine alignments in different postures. ${ }^{12}$ In the first case, the patient was morbidly obese with a body mass index of 44.07 with a normal $\mathrm{T}$ score of -1.6 . The cause of nontraumatic fracture in our patient could be multifactorial. Our patient had Nurick grading 5, with profound motor weakness and was confined to bed either in supine or sitting position. A sudden fall of any patient with lower extremity weakness from sitting to supine position is equivalent to a ground level fall in a normal individual. However, our patient did not recollect any incident of sudden jerky movement or near fall incident while changing from sitting to supine posture. In a natural sitting posture, both the lumbar spine and thoracolumbar junction tend to go into kyphosis and assume a single C-shaped sagittal profile. ${ }^{13}$ However, in a patient with long fusion, the ability to compensate within that segment is virtually absent. ${ }^{14}$ Thus, a longer lever arm with larger body weight induced a stress at the lower instrumented level, resulting in a nontraumatic unstable fracture. In the second case, the patient was averagely built with low $\mathrm{T}$ score (osteoporosis) and Nurick 5 neurological status. In

Table. List of previous literature on nontraumatic early junctional failures.

\begin{tabular}{|c|c|c|c|c|}
\hline Name of Study (y) & $\begin{array}{l}\text { Type of } \\
\text { Fracture/Level }\end{array}$ & $\begin{array}{l}\text { Previous Fusion Level and } \\
\text { Reason for Instrumentation }\end{array}$ & Proposed Cause for Failure & Management of Fracture \\
\hline $\mathrm{Hu}$ et al $(2015)^{11}$ & $\begin{array}{l}\text { Chance fracture } \\
\text { at } \mathrm{T} 2 / \mathrm{UIV}\end{array}$ & T2-L1 for thoracic kyphosis & $\begin{array}{l}\text { Osteoporosis, increased stiffness } \\
\text { of fixation, improper UIV selection }\end{array}$ & Extension of fusion to $\mathrm{C} 5$ \\
\hline $\operatorname{Tan}(2017)^{12}$ & $\begin{array}{l}\text { Compression fracture } \\
\text { at L5/LIV }\end{array}$ & T12-L5 for degenerative scoliosis & Osteoporosis, improper LIV selection & Extension of fusion to $\mathrm{S} 1$ \\
\hline Our study case 1 & $\begin{array}{l}\text { Chance fracture } \\
\text { at L1/LIV }\end{array}$ & T4-L1 for thoracic canal stenosis & Obesity and long lever arm & Extension of fusion to pelvis \\
\hline Our study case 2 & $\begin{array}{l}\text { Chance fracture } \\
\text { at L1/LIV }\end{array}$ & C7-L1 for thoracic canal stenosis & $\begin{array}{l}\text { Osteoporosis, long lever arm and } \\
\text { improper LIV selection }\end{array}$ & NA \\
\hline
\end{tabular}

Abbreviation: NA, not applicable; LIV, lower instrumented vertebra; UIV, upper instrumented vertebra. 


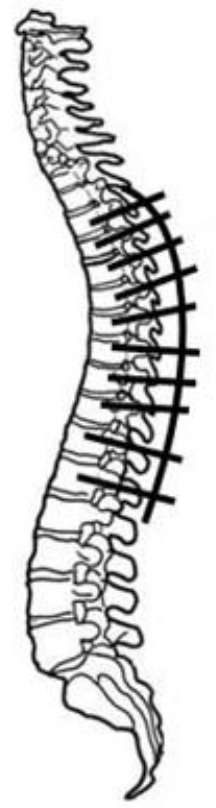

(A) SUPINE

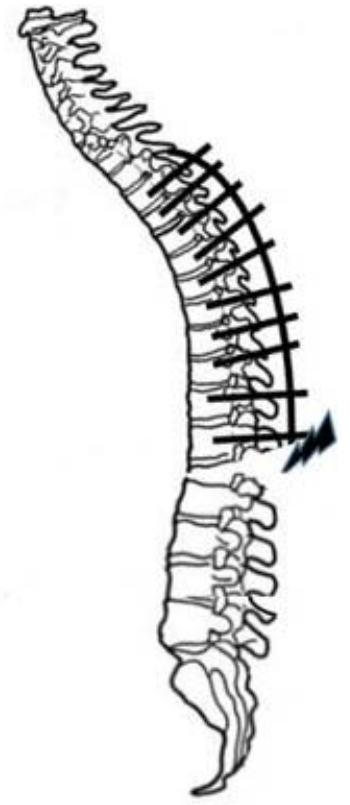

(B) SITTING
Figure 10. (A, B) demonstration of spine alignment (A) In supine position, anterior pelvic tilt with lumbar lordosis and fixed thoracic spine. (B) In sitting position, neutral pelvis with decrease in lumbar lordosis and no change in thoracic kyphosis due to instrumentation leading to stress at the LIV, resulting in failure.

addition to prolonged sitting, osteoporosis and thoracolumbar kyphosis were considered to be the cause of nontraumatic L1 fracture.

A proper selection of UIV, LIV, rod contouring, and screw density are needed in case of long level fusion surgeries to avoid junctional failures. ${ }^{15}$ Currently, the gold standard for sagittal realignment in such fusion surgeries is to restore a normal spinal curvature in the standing posture. ${ }^{16,17}$ In case 1, T4L1 posterior stabilization was done not based on the principles of deformity correction but as an adjunct to the thoracic decompression and to prevent the progression of the ossification of the posterior longitudinal ligament 1 . However, in case 2 , the preexisting thoracolumbar kyphosis, which was not considered in LIV selection, added to the cause of DJF. When an individual changes posture from standing to sitting, the sagittal vertical axis shifts forward with the body's center of gravity. ${ }^{18}$ This is associated with a reduction in lumbar lordosis, compensatory reduction in thoracic kyphosis, and lordotic changes at thoracolumbar junction (Figure 10). However, in patients who have neurological deficits and who are unable to stand, there is no clear consensus regarding the ideal sagittal alignment which must be achieved with fusion surgeries. It is more logical to decide these parameters using sitting radiographs in such scenarios for deciding the levels of fusion, rod contouring, etc.

In the first case, the supine imaging was almost normal, and the diagnosis of DJK with L1 fracture instability was demonstrated only in sitting radiograph. Though the usual type of DJF is with the pullout of screws, in both cases, there were no screw pullouts, which is evident with unaltered orientation of the screws with the vertebral body between immediate postoperative and postfailure $\mathrm{x}$ rays. This patient showed no new abnormality at the operated level; however, the patient had a lower motor neuron type of neurological deficit. This made us investigate for adjacent segment pathologies. The supine-sitting dynamic radiograph is an important tool in diagnosing the DJF in such case scenarios when the patient is unable to stand.

In retrospect, various factors were found which could have contributed to the fracture in our paraplegic patients: (1) Obesity - the larger the body weight, the higher the stress at the junctional levels. ${ }^{8}$ (2) Osteoporosis - the lesser the bone mineral density, the higher the chances of LIV fracture. ${ }^{14}$ (3) Longer levels of fusion-limited mobile areas to compensate for changes in posture and longer lever arm act as a stress riser at the lower end of fusion levels. ${ }^{14}$ (4) LIV at thoracolumbar junction-a higher amount of stress at the junctional level, especially in paraplegics who are in prolonged sitting position. (5) Sagittal malalignment - as these patients are predominantly in sitting position, preoperative sitting radiographs will help to decide the levels of fusion, rod contouring, ${ }^{19}$ screw density, etc.

\section{CONCLUSIONS}

Summarizing, these 2 cases highlight the need for further biomechanical and clinical studies to identify precisely the cause of DJK, as literature evidence is scarce. A high index of suspicion is required for diagnosing nontraumatic fracture in long level fusion patients with acute neurological worsening. Supine-sitting dynamic radiograph is an important diagnostic tool for DJF in patients with difficulty standing erect.

\section{REFERENCES}

1. Denis F, Sun EC, Winter RB. Incidence and risk factors for proximal and distal junctional kyphosis following surgical treatment for Scheuermann kyphosis: minimum five-year 
follow-up. Spine (Phila Pa 1976). 2009;34(20):E729-E734. doi:10.1097/BRS.0b013e3181ae2ab2

2. Lowe TG, Lenke L, Betz R, et al. Distal junctional kyphosis of adolescent idiopathic thoracic curves following anterior or posterior instrumented fusion: incidence, risk factors, and prevention. Spine (Phila Pa 1976). 2006;31(3):299-302. doi:10.1097/01.brs.0000197221.23109.fc

3. Cho KJ, Lenke LG, Bridwell KH, Kamiya M, Sides B. Selection of the optimal distal fusion level in posterior instrumentation and fusion for thoracic hyperkyphosis: the sagittal stable vertebra concept. Spine (Phila Pa 1976). 2009;34(8):765-770. doi:10.1097/BRS.0b013e31819e28ed

4. Cho KJ, Suk SI, Park SR, et al. Risk factors of sagittal decompensation after long posterior instrumentation and fusion for degenerative lumbar scoliosis. Spine (Phila $\mathrm{Pa}$ 1976). 2010;35(17):1595-1601. doi:10.1097/BRS.0b013e3181bd $\operatorname{ad} 89$

5. Hostin R, McCarthy I, O’Brien M, et al. Incidence, mode, and location of acute proximal junctional failures after surgical treatment of adult spinal deformity. Spine (Phila Pa 1976). 2013;38(12):1008-1015. doi:10.1097/BRS.0b013e318271319c

6. Kim YJ, Bridwell KH, Lenke LG, Glattes CR, Rhim S, Cheh G. Proximal junctional kyphosis in adult spinal deformity after segmental posterior spinal instrumentation and fusion: minimum five-year follow-up. Spine (Phila Pa 1976). 2008;33(20):2179-2184. doi:10.1097/BRS.0b013e31817c0428

7. Arlet V, Aebi M. Junctional spinal disorders in operated adult spinal deformities: present understanding and future perspectives. Eur Spine J. 2013;22(Suppl 2):S276-S295. doi:10. 1007/s00586-013-2676-x

8. Wittenberg RH, Shea M, Edwards WT, Swartz DE, White AA 3rd, Hayes WC. A biomechanical study of the fatigue characteristics of thoracolumbar fixation implants in a calf spine model. Spine (Phila Pa 1976). 1992;17(6 Suppl):S121-S128. doi:10.1097/00007632-199206001-00010

9. Lafage V, Ames C, Schwab F, et al. Changes in thoracic kyphosis negatively impact sagittal alignment after lumbar pedicle subtraction osteotomy: a comprehensive radiographic analysis. Spine (Phila Pa 1976). 2012;37(3):E180-E187. doi:10. 1097/BRS.0b013e318225b926

10. Kwon BK, Elgafy H, Keynan O, et al. Progressive junctional kyphosis at the caudal end of lumbar instrumented fusion: etiology, predictors, and treatment. Spine (Phila Pa 1976). 2006;31(17):1943-1951. doi:10.1097/01.brs.0000229258. 83071.db

11. $\mathrm{Hu} \mathrm{X}$, Lieberman IH. Proximal instrumented vertebral body chance fracture after pedicle screw instrumentation in a thoracic kyphosis patient with osteoporosis. J Spinal Disord Tech. 2015;28(1):31-36. doi:10.1097/BSD.0b013e3182694f73

12. Tan JH, Tan KA, Hey HWD, Wong HK. Distal junctional failure secondary to L5 vertebral fracture - a report of two rare cases.J Spine Surg.2017;3(1):87-91. doi:10.21037/ jss. 2017.02.09

13. Hey HW, Wong CG, Lau ET, et al. Differences in erect sitting and natural sitting spinal alignment-insights into a new paradigm and implications in deformity correction. Spine J. 2017;17(2):183-189. doi:10.1016/j.spinee. 2016.08.026

14. Berjano $\mathrm{P}$, Damilano $\mathrm{M}$, Pejrona $\mathrm{M}$, Langella $\mathrm{F}$, Lamartina C. Revision surgery in distal junctional kyphosis. Eur Spine J. 2020;29(Suppl 1):86-102. doi:10.1007/s00586-02006304-y

15. Hu SS. Internal fixation in the osteoporotic spine. Spine (Phila Pa 1976). 1997;22(24 Suppl):43S-48S. doi:10.1097/ 00007632-199712151-00008

16. Schwab F, Patel A, Ungar B, Farcy JP, Lafage V. Adult spinal deformity-postoperative standing imbalance: how much can you tolerate? An overview of key parameters in assessing alignment and planning corrective surgery. Spine (Phila Pa 1976). 2010;35(25):2224-2231. doi:10.1097/BRS.0b013e3181ee $6 \mathrm{bd} 4$

17. Lamartina C, Berjano P, Petruzzi M, et al. Criteria to restore the sagittal balance in deformity and degenerative spondylolisthesis. Eur Spine J. 2012;21(Suppl 1):S27-S31. doi:10.1007/s00586-012-2236-9

18. Hey HWD, Teo AQA, Tan KA, et al. How the spine differs in standing and in sitting-important considerations for correction of spinal deformity. Spine J. 2017;17(6):799-806. doi:10.1016/j.spinee. 2016.03.056

19. Grelat M, Du CZ, Xu L, Sun X, Qiu Y. Undercontouring of rods: a potential risk factor for proximal junctional kyphosis after posterior correction of Scheuermann kyphosis. J Neurosurg Spine. 2020;1-8. doi:10.3171/2020.5. SPINE20229

Disclosures and COI: The authors declare no conflict of interest. No financial assistance or sponsorship was received in support of the study. Anonymity of patients has been completely maintained, and no clinical pictures of patients are shown. Written consent for publishing radiological images and clinical data has been obtained.

Corresponding Author: Satish Rudrappa, Department of Spine Surgery, Institute of Neurosciences, Sakra World Hospital, Bellandur, Bangalore, Karnataka 560103, India. Phone: 919844020211; Email: drsatishr@gmail.com.

Published 0 Month 2021

This manuscript is generously published free of charge by ISASS, the International Society for the Advancement of Spine Surgery. Copyright (C) 2021 ISASS. To see more or order reprints or permissions, see http://ijssurgery.com. 